\title{
Clinical Trial Committee Member Confidentiality Disclosure Agreement
}

National Cancer Institute

\section{Source}

National Cancer Institute. Clinical Trial Committee Member Confidentiality Disclosure

Agreement. NCI Thesaurus. Code C125424.

A leg ally binding document established between the trial sponsor and a clinical trial independent committee member that contains the provisions governing the nondisclosure requirements of any/all information pertaining to the clinical trial. 